\title{
CANTO Y DESENCANTO DEL CISNE. RUBÉN DARÍO EN EL DIARIO EL ORDEN DE TUCUMÁN (ARGENTINA, 1898)
}

\author{
ANA MARÍA RISCO \\ anamrisco@gmail.com \\ CONICET-IILAC \\ Universidad Nacional de Tucumán
}

\section{Resumen}

La llegada de Rubén Darío a Buenos Aires y su participación en La Nación constituyen episodios de gran resonancia para el mundo de las letras argentinas, en cuanto a renovación de poéticas -entre naturalismo y modernismo- y dinámica social.

En el presente trabajo analizamos dos crónicas de Darío publicadas en noviembre de 1898 en El Orden de Tucumán, periódico de una provincia del noroeste de Argentina. Nuestro análisis identifica los elementos modernistas de sus crónicas y su eventual postura americanista e indigenista. A su vez, con este trabajo nos proponemos rescatar estas crónicas, desconocidas por la crítica, que permanecen en la actualidad bajo la sombra del olvido y de la indiferencia.

Palabras clave: Rubén Darío, crónica, Modernismo, El Orden, periodismo

\begin{abstract}
The Ruben Dario's arrival to Buenos Aires and his participation on La Nación are two great resonant episodes for the argentine lettered city, in the sense of a renovation of the poetics -between naturalism and modernism- and the social dynamic.

In the present paper we analyze two chronicles from Darío published in November 1898 in El Orden from Tucumán, a newspaper from a province of Northwest Argentina. In this work we identify the modernist elements of his chronicles and his americanist and indigenist eventual position. At the same time, through this work we propose recover these texts from Dario, that today are unknown from the critics, remaining under the shadow of the forgotten and the indifference.
\end{abstract}

Keywords: Rubén Darío, chronicle, Modernism, El Orden, journalism

Anales, 26, 2014, pp. 363-392

DOI: 10.14198/ALEUA.2014.26.16 
Me embarqué para la capital argentina, llevando como «valet» un huesudo holandés que sin recomendación alguna se me presentó ofreciéndome sus servicios.

Rubén Darío

\section{Introducción}

La residencia en la capital argentina a fines del siglo XIX de Félix Rubén García Sarmiento (1867-1916), conocido como Rubén Darío, representa un lugar común en el que se apoya la crítica de la literatura argentina para identificar sus huellas. No pretendemos discutir si su influencia en la producción literaria argentina comienza y termina en el lapso temporal comprendido entre los años 1893 y 1898, durante el cual Darío vivió y trabajó en Buenos Aires. En este sentido, Pedro Luis Barcia ha señalado, en ocasión del centenario del nacimiento del escritor nicaragüense (1967), el error de la crítica en circunscribir el estudio de la influencia de Darío en las letras locales exclusivamente a dicho lapso temporal (1968: 14).

Tal como la crítica ha reconocido en diversas ocasiones, no existe una verdadera obra completa que reúna y compile de forma íntegra y acabada la totalidad de la producción literario-periodística de Darío, mayormente dispersa en diarios y revistas. Asimismo, se ha señalado que las denominadas «obras completas» del autor de Azul... (1888) no son tales, pues se evidencian en ellas más omisiones que inclusiones, independientemente de quién sea el responsable de dicho desorden (Montaldo, 2013: 47-48).

Por otra parte, Darío no se constituye como pionero del modernismo en Argentina. En este punto, coincidimos con Emilio Carilla y Susana Zanetti en que no es él el que introduce el modernismo en Buenos Aires, pues La Nación ya cuenta como colaborador al propio José Martí, quien escribe para el diario de Mitre entre 1882 y 1891. En el tramo comprendido entre los años 1890 y 1891 Martí, tal como se sabe, es representante de Argentina en Nueva York en calidad de cónsul y desde allí continúa colaborando con la prensa porteña (Carilla, 1967: 158). A su vez, tampoco él es el primero que introduce la crónica modernista (chronique) en Hispanoamérica. Según señala Aníbal González, se atribuye su introducción a Manuel Gutiérrez Nájera, «seguido muy de cerca cronológicamente por Martí» (1983: 77).

Si tenemos en cuenta la inadecuada recopilación de la obra de Darío, nunca completa, metáfora de la modernidad siempre cambiante, fluctuante, laberíntica e inacabada, no sorprende encontrar escritos de su autoría, artículos con su firma publicados en diarios desconocidos en el plano internacional por pertenecer a circuitos de circulación ya inexistentes y en su origen, periféricos. 
Tal es el caso de los textos darianos aparecidos en medios periodísticos de las provincias argentinas.

\section{La crónica modernista en diarios argentinos y latinoamericanos}

Para el escritor-periodista moderno ${ }^{1}$ la crónica se constituye en su herramienta expresiva predilecta. Dicho género se encuentra atravesado por la tensión constante entre la sensibilidad del poeta y la vertiginosidad de la redacción del diario, lo que ocasiona la composición de un estilo de escritura y de vida que conjuga inseparablemente las instancias de producción literaria y periodística (Rama, 1985: 77), consecuencias propias de las tensiones que produce la vorágine de la vida moderna (Berman, [1982] 1988: 2). En efecto, el mundo moderno gira en torno a la vertiginosidad del cambio como su principio de funcionamiento y del predominio de la lógica de los intereses individuales establecida por el universo capitalista que impone su sistema de valores materialista, donde conviven los mundos contrapuestos, la dualidad, la ambigüedad y las contradicciones (Gutiérrez Girardot, [1983] 2004: 60; Rama, 1985: 56-57 y Berman, [1982] 1988: 6).

Las abundantes crónicas de Martí y de Darío conforman de por sí un corpus suficientemente significativo para indagar sobre sus vínculos con el crecimiento y el desarrollo de lo que posteriormente se ha llamado "periodismo cultural», esa zona especializada de la prensa en tensión permanente con el concepto de la inmediatez de la práctica periodística cultivada por el género de la noticia (Risco, 2009: 22). Esta especialización se deriva, como se sabe, de las consecuencias de la división del trabajo impuestas por la lógica de dependencia de la economía capitalista en la época moderna que comienzan a manifestarse en Buenos Aires (Rama: 44), acorde con el proceso histórico iniciado en Europa a partir de la expansión del capital y de la constitución de la sociedad civil. Este fenómeno ha sido señalado por Gutiérrez Girardot, citando la prosa del mundo de Hegel (44-46); y también como lo ha señalado Marshall Berman a través de una propuesta de tres fases históricas de la modernidad (3).

Esta abundancia de producción periodística resulta una constante también presente en otros autores modernistas como Manuel Gutiérrez Nájera, Julián del Casal, Enrique Gómez Carrillo, Leopoldo Lugones y Ricardo Jaimes Freyre, entre otros. En este sentido, Graciela Montaldo señala la existencia de un mito entre los estudiosos acerca de la producción de los escritores modernistas, que disocia la labor de la prensa de la producción literaria. Montaldo

1. Categoría que adoptamos de Zanetti (2004: 13).

Anales, 26, 2014, pp. 363-392 
sostiene la convivencia de ambas como tareas intercaladas. En efecto, usualmente se considera que la labor periodística de los modernistas constituye el sustento económico que permite a los escritores mantener su labor literaria (2013: 13); en definitiva, les brinda una «subsistencia cómoda» (Carilla, 1967: 19). La producción febril de los escritores modernistas en las redacciones de los diarios constituye una justificación de las exigencias laborales, propias del momento de emergencia de especializaciones profesionales diferentes. ${ }^{2}$ Ángel Rama y Rafael Gutiérrez Girardot reconocen las tensiones de dicha labor intelectual en el mundo periodístico de los escritores modernistas.

La consideración de la escritura como enfermedad se potencia en el modernismo de fin de siglo en relación con la producción febril mencionada, asociada con el intenso trabajo en el periódico. Según Carlos Battilana, «la enfermedad del diario», de la que habla Darío, ${ }^{3}$ se deriva del nerviosismo propio de la vida vertiginosa en la redacción del periódico, generado por el nuevo lugar de trabajo. Este tipo de padecimiento es percibido como una nueva modalidad de la «enfermedad de la sensibilidad», según la taxonomía psiquiátrica de la época. Se trata, fundamentalmente, de la enfermedad provocada por una escritura bajo presión que implica «domesticarse en una labor constante» (2004: 126). Battilana aclara que la «enfermedad del diario» no debe ser homologada a la de los escritores literarios, pues esta última proviene de una sensibilidad extrema. Dicha «enfermedad del diario» sería, a su vez, una consecuencia de lo que Georg Simmel llama la «intensificación de los estímulos nerviosos» producida por la vida de la metrópoli sobre la actividad mental (Simmel, 2005: 2). La consecuencia típica de esta sobre-estimulación nerviosa es la «actitud blasée» (Blasierheit) (Simmel, 2005: 4 y 1903: 193), esa indiferencia basada en el hastío, producto de la incapacidad cerebral de procesar la inmensa cantidad de estímulo externo, ${ }^{4}$ actitud hacia la que no parece derivar la «enfermedad del diario» de la escritura modernista señalada por Battilana.

2. Seguimos la terminología empleada por Raymond Williams (2000 [1977]).

3. «La enfermedad del diario» (La Quincena, 1897) (Mapes, 1938: 148-152).

4. «Es gibt vielleicht keine seelische Erscheinung, die so unbedingt der Großstadt vorbehalten wäre, wie die Blasiertheit (...) Wie ein maßloses Genussleben blasiert macht, weil es die Nerven so lange zu ihren stärksten Reaktionen aufregt, bis sie schließlich überhaupt keine Reaktion mehr hergeben - so zwingen ihnen auch harmlosere Eindrücke durch die Raschheit und Gegensätzlichkeit ihres Wechsels so gewaltsame Antworten ab, reißen sie so brutal hin und her, dass sie ihre letzte Kraftreserve hergeben und, in dem gleichen Milieu verbleibend, keine Zeit haben, eine neue zu sammeln» (Simmel, 1903: 193). 
Para los escritores, no obstante el nerviosismo y la vertiginosidad de la redacción, el diario representa un espacio de amplificación de las modalidades de su trabajo experimental con la escritura, un escenario de legítima circulación y un lugar en el cual el trabajo intelectual encuentra una función concreta y satisface una necesidad dentro del sistema capitalista (Rama, 1985: 77). Dicha amplificación se percibe a través de la crónica modernista, que acoge la heterogeneidad discursiva derivada de la diversidad cultural desordenada, fragmentaria (Battilana, 2004: 127). Esta confluencia de estilos y discursos es interpretada por Ángel Rama como un sincretismo artístico (1985: 79), que mezcla las posibilidades estilístico-literarias con la escritura periodística. Esta heterogeneidad discursiva o sincretismo de estilos sería, a nuestro entender y siguiendo el razonamiento de Simmel, la respuesta de los modernistas a la intensificación nerviosa provocada por la dualidad de la tensa vida moderna, por el sobre-estímulo al que el escritor se ve sometido, física y mentalmente.

En el espacio del diario, el discurso de la crónica es un terreno de disputas por la legitimidad del estilo entre periodistas y escritores. Dicha disputa produce una disonancia, un quiebre, que a su vez se torna necesario en el camino de la diferenciación de áreas especializadas de la actividad cultural. Sobre este punto no existe un acuerdo: los escritores construyen las crónicas de acuerdo a una estética que, si bien se diferencia sustancialmente del lenguaje literario de los géneros tradicionales, se preocupa por una sintaxis elaborada, por construcciones de imágenes con pinceladas estéticas, mientras que a los periodistas se les reprocha su falta de interés por el cuidado del estilo y su escritura a-estética, despojada. Periodismo versus literatura es el debate central en las páginas de los diarios en la última década del XIX y las postrimerías del $\mathrm{xx}$, un debate que focaliza la competencia discursiva de los trabajadores de la escritura.

Concretamente, en dicho debate resalta la función de la crónica como género literario-periodístico, lo que problematiza la relación entre periodismo y literatura. En el ámbito del diario, en la crónica «se origina una zona intersticial que da lugar a la heterogeneidad donde se mezclan, articulan y disuelven al mismo tiempo sus límites discursivos» (Battilana, 2004: 130). Heterogeneidad, no heteronomía, según sostiene Julio Ramos. En este sentido, la crónica modernista se presenta como un espacio de disputa entre distintas autoridades (estética y periodística), donde la estetización se sostiene como política de autonomización literaria, a pesar de ser evidente su dependencia con el periódico que la limita porque allí mismo es donde se produce y circula (Ramos, 2009: 179). 
A su vez, el antagonismo en el plano laboral y escritural entre literatos y periodistas que comparten el espacio de la redacción y de las páginas de los diarios se fundamenta, no sólo en las nuevas autoridades escriturarias, sino también en la lucha de «los intelectuales "tradicionales" (en el sentido gramsciano) contra los escritores "orgánicos" del nuevo mercado de la información» (Ramos, 2009: 194).

La crónica se torna la herramienta escritural esencial tanto para periodistas como para literatos. En el terreno literario, según Ramos, se constituye en un género menor. Entre las características de su modalidad modernista cultivada por Martí, Gómez Carrillo, Gutiérrez Nájera y Darío, entre otros, Ramos analiza las siguientes:

1) la representación de la vida urbana (de ahí su forma epistolar y su vínculo con la literatura de viajes);

2) la escritura de la cotidianidad del mundo capitalista (sobre todo Martí en sus Escenas norteamericanas);

3) el cronista como guía refinado del mercado del lujo y de los bienes culturales;

4) la «retórica del consumo» en la descripción estetizada de los objetos del mercado destinado a un público burgués que ha reeducado su gusto - «el fetichismo de la mercancía se representa como experiencia estética» (Ramos, 2009: 218), sobre todo en Darío;

5) la fragmentación y la narrativización de la experiencia urbana que manifiesta los vaivenes propios del estilo conversacional, haciendo explícita la oralidad de base y articulando, por momentos, la dialéctica entre «un interior ${ }^{5}$ metafórico del repliegue literario del sujeto, cuya materialización discursiva se manifiesta en la escena de la alcoba, la biblioteca o el despacho como «refugio del arte» (González, 1983: 109), y «un exterior» de la vida urbana que se debe relatar, el de la ciudad contemplada, que constituye la parte informativa propiamente dicha de la crónica de un diario (Ramos, 2009: 208);

6) el empleo de la «retórica del paseo» a través de la cual se impone la perspectiva del paseante, constituyéndose el paseo como un nuevo modo de recreación en la ciudad moderna. El sujeto discursivo se convierte en un cronista-flâneur -siguiendo a Benjamin-, ${ }^{6}$ para quien la vitrina de exposición de la mercancía se transforma en el objeto preferido, como metáfora «mediante

5. «Interior» remite al «interieur» señalado por Walter Benjamin y retomado por Rafael Gutiérrez Girardot cuando identifica los dos mundos configurados en la «novela del artista» por los escritores modernos (Gutiérrez Girardot, 2004: 58).

6. El cronista-flâneur que señala Ramos es una derivación directa del Flâneur que Benjamin identifica en Charles Baudelaire. Cfr. Benjamin (2012: 56 y 57). 
la cual cierta escritura finisecular (particularmente en la crónica) autorrepresenta su sometimiento a las leyes del mercado» (Ramos: 250).

Para Darío, la crónica se constituye como el espacio experimental preferencial donde ensayar los cruces entre literatura y periodismo (Rama: 77), una modalidad de la relación entre cultura y divulgación, relación que ya comienza a perfilar un papel significativo en la conformación de un público anónimo y abundante propio de la llamada e incipiente «sociedad de masas» (Montaldo, 2013: 14-15).

El interés de Darío por ingresar a la dinámica de un mercado literario se ve reflejada en las observaciones hechas con posterioridad a su residencia en Argentina, como corresponsal de La Nación en España ${ }^{7}$ y Francia. En una de sus colaboraciones reconoce la necesidad de considerar las demandas del público popular, sus gustos. En 1905 sugiere, en cierta forma, seguir los pasos de Madrid Cómico, captador de dicho gusto. Ello justificaría su afirmación en Cantos de Vida y Esperanza de que las innovaciones literarias de la época en España se encuentra en manos de «los poetas del Madrid Cómico y los libretistas del género chico» (Montaldo, 2013: 26). Tal como afirma la crítica, son una constante en sus obras las referencias de Darío al gusto del público y al creciente consumo, muestras de la necesidad del escritor de ingresar en la dinámica de un mercado cultural incipiente en Argentina. Recordemos que para Rama el mercado literario en América Latina a fines del siglo XIX aún no existía (52). Esta situación varía hacia 1907 cuando Darío reconoce que vende libros y que también es víctima de la piratería literaria, es decir, ha ingresado en un mercado literario del cual obtiene pocos beneficios (55).

Según Zanetti, las crónicas de Darío son del agrado del público. Las claves se encuentran en ciertos detalles que constituyen su estilo, como la inclusión del lector en el propio texto de la crónica; el empleo de la ironía (en complicidad con el lector culto), del humor, de coloquialismos porteños (localizando la recepción de la crónica); y la preferencia por una prosa liviana, impregnada de episodios de vivencia cotidiana mezclados con referencias letradas del mundo fantástico y del grecolatino (2004: 15-18).

A este gusto del público responde, además, la convivencia en las páginas de La Nación de las crónicas de Darío con los folletines de Dumas y de autores costumbristas y realistas argentinos. Dicha coexistencia se torna posible gracias al concepto amplio de cultura que promueve el mismo diario. Sin

7. En diciembre de 1898 parte Rubén Darío a España como corresponsal de La Nación de Buenos Aires con el propósito de informar sus impresiones sobre la repercusión de la guerra entre España y Estados Unidos de Norteamérica por Cuba (Henríquez Ureña, 1978: 102). 
embargo, si bien el diario acoge en sus páginas novelas por entrega, en la sección del folletín se selecciona el material correspondiente a la vertiente considerada culta. Según Mogillansky, el mismo Roberto J. Payró reconoce la exclusión de los folletines populares, «género vulgarizado» por los «folletinistas profesionales» del estilo de Eduardo Gutiérrez (2004: 90). Esto mismo sucede en algunos periódicos de provincia que toman como modelo $\mathrm{La} \mathrm{Na-}$ ción y La Prensa de Buenos Aires, como es el caso de El Orden de Tucumán.

\section{Relato de un cosmopolita: las crónicas de Darío exclusivas para El Orden de Tucumán}

Durante el mes de noviembre de 1898 el vespertino tucumano El Orden se congratula por haber conseguido a Rubén Darío como colaborador. Desde sus inicios en 1883 bajo la dirección de Ernesto Colombres, el fundador del diario, ${ }^{8}$ el equipo redactor se preocupa por incorporar escritores y personalidades destacadas del ambiente cultural. La labor de conseguir firmas se lleva a cabo durante las estancias del director del diario en la capital argentina, ocasiones que aprovecha para relacionarse con letrados y políticos de la época. Su posición privilegiada en la elite político-económica de la provincia es la clave de su acceso a los círculos culturales de Buenos Aires, en los cuales logra llamar la atención. A su vez, sus relaciones como hombre de prensa le permiten vincularse con las redacciones de los diarios porteños hegemónicos del ambiente periodístico de la época, a saber, La Nación y La Prensa. Las relaciones y vínculos con los comprovincianos residentes en Buenos Aires, muchos de los cuales ocupan cargos políticos oficiales, es otro de los aspectos que favorece la atención de la elite cultural porteña. El perfil político editorial del diario en esta época es conservador.

Acorde con un concepto ilustrado de cultura, el diario de Colombres busca establecer vínculos letrados entre el interior y la capital persistentes en el tiempo, incluso después de retirarse su fundador debido a su carrera política, quien asume una banca en el Congreso como Diputado Nacional por Tucumán. En 1887 León M. Rosenvald, que ejercía como reporter del diario

8. El 14 de noviembre de 1883 Ernesto Colombres, político y periodista perteneciente a la elite patricia y empresarial de Tucumán, funda el diario El Orden. Según Manuel García Soriano, escribieron en sus páginas las firmas más prestigiosas que pasan por Tucumán al punto de que «era un honor ser redactor de ese diario» (1972: 31). El 16 de marzo de 1886, Ernesto Colombres se retira de la dirección del diario para dedicarse a su carrera política. En 1887 asume León M. Rosenvald como administrador responsable del diario, en reemplazo de Félix Corrales Sánchez de la Serrana (García Soriano, 1972: 32). 
desde su fundación, se erige en su conductor central. El vespertino tucumano se convierte rápidamente en un espacio de posibilidad de existencia y subsistencia de la escritura literaria de nuevos escritores locales junto a firmas consagradas. Sin embargo, la preocupación por sostener la cuota de literatura en cada entrega de la publicación se ve afectada a partir de 1887, cuando el diario debe cerrar sus puertas y reabrir con un cambio significativo en su política cultural. Entre 1887 y 1894 la literatura se encuentra prácticamente ausente de sus páginas y se dedica el mayor espacio posible al debate político y a los anuncios publicitarios de empresas locales y nacionales. La dirección del diario se torna itinerante entre los jefes de redacción, los amigos y periodistas de confianza del diario y los hijos de Rosenvald, debido a cuestiones de salud del director o a las ausencias significativas ocasionadas por la privación de su libertad por conflictos políticos locales. La línea política de la editorial del diario ha variado poco desde sus inicios. A fines de la década del noventa comienza a identificarse con los postulados políticos de la Unión Cívica promovidos por Leandro Alem y, posteriormente a su muerte (1896), con los de la Unión Cívica Radical. ${ }^{9}$

Luego de la ausencia significativa de publicación de literatura entre 1887 y 1894, salvo una mínima intervención en la sección del folletín del diario en 1894, comienzan a aparecer gradualmente poemas y cuentos entre 1895 y 1897. Recién en 1898 se reanuda plenamente la actividad literaria en el diario, publicando con mayor regularidad la sección del folletín e incorporando en cada entrega una crónica firmada por alguna personalidad reconocida, ya sea por su labor literaria, ya sea por su trayectoria periodística. La presencia cada vez mayor de escritores-periodistas en sus páginas es un índice de que la cuestión de la especialización tendiente a la futura profesionalización y

9. La Unión Cívica nace como partido político a fines del siglo XIX. En 1879 es presidido por Leandro Alem. El partido busca contrarrestar la política dominante del general Roca, establecida desde 1880, y su continuidad con ciertas modificaciones durante la presidencia de Juárez Celman. Luego de la revolución de 1890, la Unión Cívica se divide entre los acuerdistas, es decir, aquellos partidarios que avalan el acuerdo entre Mitre y Roca, quienes constituyen la Unión Cívica Nacional, presidida por Bonifacio Lastra; y los anti-acuerdistas que conforman la Unión Cívica Radical con Alem como presidente (Persello, 2011: 81-82). Con la muerte prematura de Alem en 1896 el partido pierde fuerzas. Posteriormente es reorganizado por un grupo de políticos con fuerte postura crítica y apoyo popular. La Unión Cívica Radical, gracias a la ampliación de la ley electoral en 1912 y con el favor de dicho apoyo popular, alcanza la presidencia con Hipólito Yrigoyen en 1916 (Alonso, 2000). Esta línea política iniciada en 1890, luego de la revolución que derroca a Juárez Celman, constituye lo que posteriormente se conoce como el radicalismo o partido radical, que domina la administración estatal hasta el primer Golpe de Estado de 1930. Al radicalismo se opondrá a mediados del siglo XX, aproximadamente, el partido popular liderado por el general Juan Domingo Perón. 
diferenciación de campos laborales y de especificación del saber dentro del diario comienza a hacerse sentir, aunque en sus páginas no se debate sobre la problemática del escritor profesional de la misma forma que en La Nación.

Entre las crónicas publicadas por el diario tucumano sobresalen las cartas enviadas por Rubén Darío, anticipadas por un anuncio en el que se destaca la importancia de su inclusión. Así es como el miércoles 2 de noviembre de 1898, en la segunda página de El Orden, una nota breve titulada «Rubén Darío» notifica la incorporación del escritor nicaragüense como colaborador del diario y anuncia la publicación de su crónica:

EL ORDEN incorpora al número de sus elementos intelectuales uno de primera fuerza.

Rubén Darío, el discípulo de Verlaine, el poeta original y fecundo, el literato que tantas caricias de las Musas ha recibido, en su corta y brillante carrera, entra á formar parte de nuestros colaboradores, vertiendo en las columnas de EL ORDEN, el oro en polvo de su privilegiado intelecto.

Mañana publicaremos la primera carta metropolitana que nos envía. ( Rubén Darío», El Orden, 02/11/1898: 2) ${ }^{10}$

Si nos detenemos en este anuncio, observamos que el diario remarca entre «sus elementos intelectuales» a Darío. Tal como se deduce del fragmento citado, la condición de «intelectuales» se define por un «privilegiado intelecto» y por vivir gracias a su producción mental. En esta presentación no se menciona que Darío forma parte de la redacción de La Nación ni se alude a su vasta producción en la prensa argentina y latinoamericana de la época. En ella se promete publicar las crónicas enviadas por el autor exclusivamente para El Orden, bajo la forma de «cartas metropolitanas». Con esta denominación se resalta el carácter urbano y cosmopolita de la crónica modernista, captado en el preciso momento de su auge. Evidentemente, el peso simbólico de la firma del poeta resulta más atractivo que su trayectoria como cronista y corresponsal del diario de Mitre. En esta omisión se percibe una solapada disputa en la competencia de la posesión del capital cultural que representa la producción literario-periodística de Darío, entre un periódico de capital de una provincia norteña y el ya consagrado y hegemónico diario de Buenos Aires.

Presentado como poeta de filiación verlainiana, El Orden destaca la importancia y trayectoria literaria de Darío, sin proporcionar mayores detalles por considerarla lo suficientemente conocida por el público del diario:

Recomendaremos su lectura? Para qué! Si Rubén Darío es uno de los escritores que no necesitan presentaciones ni elogios; es uno de esos intelectuales

10. En el presente trabajo se respetan y mantienen la ortografía y giros lingüísticos del original. 
que se imponen en el campo de las letras y de quien puede decirse que en la literatura argentina su firma representa lo que la rúbrica real en los países monárquicos: todos la acatan.

Nuestros lectores han de agradecernos el nuevo concurso con que se enriquece EL ORDEN, al tener ocasion de deleitarse con las hermosas producciones de uno de los mas escogidos talentos que florecen en el Plata («Rubén Darío», El Orden, 02/11/1898: 2).

En el fragmento citado se pone en evidencia la conciencia del diario sobre el peso simbólico de la firma del escritor, ya que la considera la «rúbrica real» a la que «todos» rinden tributo. Finalmente, el diario exhorta al público a la lectura de los textos de Darío. Sin señalar su origen extranjero, se destaca la injerencia del escritor en el ámbito literario argentino.

La nota cierra generando expectativa en el público lector al poner énfasis en el esteticismo de su escritura y asegurar la lectura en sus páginas de «las hermosas producciones de uno de los más escogidos talentos». En definitiva, sella la presentación con la promesa del contacto del público con un privilegiado de las letras, suma distinción para un diario de provincia.

El jueves 3 de noviembre de 1898, tal como lo anticipara el diario en la presentación del día anterior, se publica la carta anunciada de Darío, en el lugar destacado junto al editorial del diario de la primera página, con fecha del $1^{\circ}$ de noviembre. Lleva como título la indicación de su remitente: «De Rubén Darío». En la línea siguiente, se imprime entre paréntesis la aclaración de exclusividad que resulta fundamental en los diarios de la época: «(Para EL ORDEN)». ${ }^{11}$ La carta contiene una presentación y exposición sobre su intervención en el diario tucumano y desarrolla cuatro núcleos temáticos: el primero, sobre la inauguración de la Exposición Nacional de 1898 en Buenos Aires, presidida por el recientemente reelecto presidente Julio Argentino Roca; el segundo núcleo gira en torno a un homenaje a Carlos Carlés; el tercero, sobre la visita del ministro español Julio Arellano y Arróspide; y el cuarto, sobre sus impresiones de un libro de Belisario J. Montero. Analizamos a continuación el contenido de la crónica de acuerdo al orden lineal de su enunciado.

En el texto de la crónica, resalta la fragmentación discursiva evidente a través del tratamiento de diversos tópicos aparentemente no conectados. El cronista anuncia que hablará de «Hechos, cosas y hombres». En la segunda oración, se explicita la circunstancia de enunciación de las cartas enviadas al diario tucumano:

Hechos, cosas y hombres, á través de mi impresión, vereis en estas cartas. Se me encarga la labor de poneros delante de los ojos, en mi prosa, á Buenos

11. El diario se menciona a sí mismo indistintamente en versalitas o en mayúsculas.

Anales, 26, 2014, pp. 363-392 
Aires, cada diez o quince dias. Os diré lo que observe en este gran centro, clara y sencillamente, presentándoos mis ideas como ellas vayan apareciendo, aisladas ó en tropel, desnudas ó lujosas. No gusto de la política, pero me acercaré á su morada, veré por entre las cortinas, por las rejas de las ventanas, y os diré lo que mire (Darío: «De Rubén Darío», El Orden, 03/11/1898: 1). ${ }^{12}$

La anticipada y aparente fragmentación del discurso con que Darío advierte al lector sobre el contenido de su texto, justifica la diversidad temática y los saltos de un tópico a otro entre parágrafos no conectados.

El autor explicita el motivo de su participación en el diario: un encargo, una petición de colaborar con crónicas sobre Buenos Aires para ser leídas por el público tucumano. De sus palabras se deduce que la única exigencia que se le impone es un envío regular «cada diez o quince dias». En este punto, Darío pone de manifiesto la labor de reclutamiento de firmas consagradas llevada a cabo por el jefe de redacción o por el director del diario. No identifica al responsable del pedido, sino que pone énfasis en el pedido mismo como un «encargo», «una labor».

En esta suerte de auto-presentación e introducción de la misiva se destaca el carácter urbano de la crónica, determinada por la naturaleza del encargo: se le solicita cartas con novedades e impresiones del «gran centro». Él, poeta mundano, cronista cosmopolita, no se resiste a tal solicitud. La gran protagonista, la ciudad, queda igualmente presentada en este preámbulo introductorio bajo la mirada de Darío. Es su mirada lo que específicamente quiere transmitir El Orden. En esa mirada y en ese estilo se encuentra el capital simbólico del que tanto se enorgullece el periódico el día anterior. Darío es consciente del valor de su escritura y lo desenmascara: «mi impresión», «mi prosa», «mis ideas», «lo que mire». En definitiva, saca a la luz que se le solicita impresiones de la ciudad en una crónica que revele la maestría de su estilo.

Nuevamente podemos observar la autoconciencia y explicitación de la construcción del texto por medio de la mención del estilo entre esteticista y despojado, propio de la crónica modernista y punto candente de discusión entre literatos y periodistas: «presentándoos mis ideas como ellas vayan apareciendo, aisladas ó en tropel, desnudas ó lujosas» (Darío, El Orden, 03/11/1898: 1).

La explicitación voluntaria de una subjetividad autoconsciente de su valor simbólico que intencionalmente inscribe marcas en el discurso, dejando huellas de una fuerte presencia autorial, pone en evidencia una introspección, un interior que observa el afuera. Esta operación de exposición de la mirada

12. Lo resaltado en cursiva me pertenece. 
íntima (sus impresiones) aproximaría el estilo de Darío a un impresionismo que inmediatamente se cuestiona y contradice. Por medio de la perspectiva situada, enmarcada, se inicia el distanciamiento del cronista de su interior en busca del observador alejado que disfruta de un espectáculo externo. La mirada de este espectador se sitúa «detrás de las cortinas», "por las rejas de una ventana», interiorizando el espectáculo aparentemente objetivado para relatar su impresión. La estrategia del encuadre, de encerrar en un espacio interior, en un cuadro observable un exterior aparentemente inabarcable, es uno de los recursos frecuentes de las crónicas de Darío.

En el segundo párrafo de su presentación, Darío se reconoce observador social, aunque más especializado en arte y literatura. Cabe destacar que no promete «juzgar» a través de su mirada, sino «charlar», como en una conversación entre amigos, sobre temas diversos: «[...] de arte y de literatura de cuando en cuando conversaremos. En fin, á la manera de un amigo lejano que comunica sus sensaciones e ideas que le sugieran las cosas, los sucesos, las gentes, así seré y mi justo deseo es que mis cartas os sean gratas» (Darío, El Orden, 03/11/1898: 1). En este cierre de la presentación, se evidencian, por un lado, otro rasgo de las crónicas modernistas: la tónica y la estructura conversacional predominante; por otro lado, la preocupación, también recurrente en la escritura de Darío, de agradar al público lector, en un acto de consciencia de su creciente poder en el incipiente mercado cultural de la época.

Sobre los cuatro temas abordados por Darío, observamos que, en el primer núcleo, predomina la cuestión del ascenso de Julio Argentino Roca ${ }^{13}$ como presidente de Argentina para un segundo mandato (1898-1904) en medio de un conflicto político interno. Darío se inmiscuye en política y destaca el hecho de que sea Roca quien inaugura la controvertida y polémica Exposición Nacional de 1898. En este apartado, el cronista se detiene en exaltar la grandeza industrial argentina y exhorta a su mantenimiento y apoyo por parte del Estado, bajo plena garantía pacífica.

13. Julio Argentino Roca (1843-1914), fue político, militar y estadista argentino, oriundo de la Provincia de Tucumán. Organizó y llevó a cabo las últimas campañas de desalojo indígena del sur argentino conocidas como «Conquista del Desierto». Fue elegido presidente argentino en dos oportunidades: 1880-1886 y 1898-1904 (Galasso, 2000). Ha sido considerado como el más importante artífice de la transformación moderna de Buenos Aires. Si bien Darío es testigo del paso de la «Gran Aldea» a la «cosmópoli», como él denomina a la capital argentina, recordemos que el lapso de tiempo que vive en Buenos Aires entre 1893 y 1898, no le permite experimentar las diversas facetas por las cuales será juzgado el general Roca por la posteridad, sino solo arriesgar hipótesis sobre el tema del pacifismo estatal. 
El evento mencionado por Darío resulta significativo. En su producción posterior abordará el tema de las exposiciones mundiales con particular interés y como nexo entre escritura y modernidad, sobre todo en la Exposición Mundial de París de 1900 (Ramos: 216). Según Diego A. Ballestero, a partir de la segunda mitad del siglo XIX las grandes exhibiciones industriales y comerciales constituyen no sólo el espacio de promoción de la producción y avances tecnológicos en pro del progreso mundial y nacional, sino también un medio de atracción y divertimento popular. En dichos eventos se encuentran involucrados industriales, empresarios del espectáculo y comerciantes avalados por el apoyo estatal (Ballestero, 2012: 790).

Entre el 16 de octubre y el 20 de noviembre de 1898 se lleva a cabo en Buenos Aires la Exposición Nacional de la Industria Argentina, que tuvo problemas en su organización y cuya realización, prevista originalmente entre el 9 de julio y el 9 de octubre de 1898, se vio amenazada. A esas dificultades organizacionales hace referencia Darío al comienzo de su texto. De otros sucesos de esta exposición se ocupa en la segunda carta, que analizaremos enseguida.

La exposición que visita en Buenos Aires constituye la excusa ideal para exaltar las manifestaciones de la modernidad, sello propio de Darío, pues considera el evento como una «fiesta y certamen de fuerza y ufanía de este país» (Darío, El Orden, 03/11/1898: 1). En un solo párrafo el autor sintetiza los conflictos de organización para resaltar inmediatamente la persistencia de los organizadores y el éxito del evento. En ese mismo párrafo elogia la grandeza de Argentina como país de desarrollo excepcional americano «de habla no inglesa». Nótese esta forma de definir lo latinoamericano por su diferencia idiomática con respecto a Estados Unidos de Norteamérica.

La información objetiva de la crónica se encuentra sintetizada en una oración intercalada con párrafos subjetivos. Así, Darío proporciona información de modo solapado sobre el lugar de emplazamiento del evento: la Plaza San Martín o del Retiro en el Pabellón Argentino, desmontado de París en 1890 y trasladado e instalado en Buenos Aires en 1893. ${ }^{14}$

Darío emplea comparaciones, analogías, metáforas, en busca de un estilo más cuidado. La caracterización del edificio donde se realiza la exposición como «Palacio de cuento de Oriente» es una analogía con fuerte carga literaria, si se tiene en cuenta la preferencia del escritor por el mundo antiguo, tanto grecolatino como oriental. Tal comparación es un resultado de la

14. Dicho Pabellón se construyó originalmente para la Exposición Universal de 1889 de París y se encontraba ubicado al lado de la Torre Eiffel. 
observación del estilo arquitectónico del edificio, como se puede constatar en las fotografías que se conservan como testimonio de la época. En efecto, se trata de un edificio de arquitectura de estilo árabe. Se podría pensar que Darío aprovecharía tal referencia para divagar por el mundo mitológico de los palacios y doncellas cautivas. Sin embargo, el cronista no profundiza, en esta oportunidad, en dichas fantasías. En este sentido, el estilo cobra importancia como tal, privilegiando lo que podría considerarse como un afán de síntesis estilizado. Síntesis que permite pasar rápidamente a otro tema, como en una conversación de café.

A modo de cámara cinematográfica, con un recurso similar a la actual perspectiva subjetiva fílmica, el relato se detiene en detalles en los que reposa una mirada particular como en ciertos efectos de luz que acompañan la escena. Progresivamente se va incorporando, adentrando en la Exposición, haciendo ingresar al lector en sus galerías: «La alegría de la luz y lo pintoresco atrayente os vencen y vais á visitar las galerías» (Darío, El Orden, 03/11/1898: 1).

Descarta la posibilidad de comparar esta muestra argentina con las grandes exposiciones "yankees o europeas», pues le resulta una operación infantil y desequilibrada. Enseguida destaca que a pesar de la «limitada extensión» y teniendo en cuenta su «legítimo incremento» (Darío, El Orden, 03/11/1898: 1), resulta elogiosa la industria nacional, en un gesto concesivo de los progresos y cambios modernos asociados a la sociedad burguesa que al mismo tiempo rechaza. Darío emplea la ejemplificación para ilustrar sus afirmaciones, lo que evidencia el lado ensayístico de la crónica: las máquinas que se producen en Argentina, la mayoría de las cuales antes sólo se importaban, representan un signo evidente del progreso industrial del país.

El autor opta por no detallar cada sección de la muestra «para no cansaros», "para no cansarme», en un claro afán de agilizar la redacción. Inmediatamente sintetiza su opinión: «existe una industria argentina que no se sospechaba», y desliza un mensaje para los dirigentes políticos y para los industriales: "país que como este cuenta con esas corrientes de vitalidad y de energía, debe procurar mantenerse en la existencia productiva de la paz, sin temor alguno y confiado en la cordura y buen pensamiento de sus hombres dirigentes» (Darío, El Orden, 03/11/1898: 1).

A continuación, en el desarrollo de los tres núcleos temáticos siguientes, observamos que el autor selecciona subjetiva y arbitrariamente las personalidades de las que se ocupará en cada uno de ellos. Dicha selección se realiza a partir del conocimiento personal de las figuras y de su proximidad afectiva, principalmente por su relación de amistad. 
De este modo, en el segundo núcleo, se detiene en la vida social porteña de la época, durante el banquete de homenaje al Dr. Carlos Carlés. Nuevamente, proporciona muy poca información objetiva del evento, sintetizada en frases breves, como ser la cantidad de comensales (300 personas) y el lugar donde se lleva a cabo la fiesta (el Prince George's Hall). El tono elogioso en la caracterización del Dr. Carlés se justifica por el conocimiento personal del autor y por su relación de amistad entablada durante el ejercicio como secretario personal de quien fuera Director General de Correos y Telégrafos de Argentina. Según el mismo Darío, Carlés es quien le otorga trabajo como secretario en un momento de suma necesidad (Darío, Vida, 1913: 203).

El tercer núcleo temático, un poco más extenso, trata sobre la visita y audiencia pública del nuevo ministro español Julio Arellano y Arróspide. ${ }^{15}$ Nuevamente, la selección del personaje se basa en la experiencia personal de Darío. Arellano es construido elogiosamente, construcción basada en su conocimiento como diplomático en América Central, y por su vínculo de amistad y familiaridad. La esposa de Arellano, Margarita Foxa, es madrina de uno de los hijos de Darío, tal como él lo recuerda en su autobiografía (1913: 99). El cronista señala lo maravilloso de la vida y carrera del ministro, que considera digna de «hermosas páginas» de novela. Destaca la vida de aventuras viajeras de los diplomáticos por lejanos países exóticos como los de oriente. A renglón seguido, llama la atención sobre una experiencia similar con otras culturas no europeas ni orientales, como la de los países tropicales de Centroamérica, en particular San Salvador. Darío exhorta a escribir una narración sobre esta experiencia, narración necesaria sobre la que divaga brevemente para luego demostrar a qué se enfrentó el diplomático español en su paso por estos países, relato que anticipa el «realismo maravilloso» del siglo XX:

Lo pintoresco, en verdad, no faltaría; la pintura de costumbres poco estudiadas, de políticos y gobiernos imposibles, en unas Américas diminutas, en que caben todas las agitaciones de los imperios bárbaros, reducidas al personal de una opereta; Gengis Khan en Lilipucia; intrigas indescriptibles, embrollos y pompas, semi primitivas; una ausencia absoluta del conocimiento de la vida actual del mundo; la organización administrativa reemplazada por el favor de los militares triunfantes y temidos; el imperio de los advenedizos; la diplomacia y el gobierno á merced de la malicia natural de los caciques; sangre, discursos, doctores en derecho y coroneles; un medio en el que lo que sobresale, ó huye, ó se achata, ó se pierde, ó se suicida. Y sobre todo eso un sol de fuego, el del trópico, y el vaho del boa yankee. Allí, en ese medio, se

15. Julio Arellano y Arróspide, diplomático español, que fuera nombrado posteriormente marqués de la Casa Arellano, fue embajador de España en Costa Rica (Rivera Montealegre, 2012: 81). 
encontró el señor Arellano en momentos muy tempestuosos. Conoció todas esas figuras que aguardan al sociólogo anatomista que las diseque. Anduvo entre aquellas gentes; evitó, por cierto, mas de un hecho atroz, y puso paz entre los jefes mestizos. Concurrió a que Guatemala y el Salvador no se trabasen en otra guerra más, y redactó él mismo las bases del arreglo pacífico. Por eso, entre mis paisanos -porque ya sabéis, creo, que yo he nacido en Centro América- le estimó mucho la gente de cultura y fué querido por todos

(Darío, El Orden, 03/11/1898: 1).

En el fragmento citado se observa el empleo de la ironía y la plena manifestación de la estilización de la crónica. Se destaca la caracterización despectiva que realiza Darío de sus compatriotas nativos como dirigentes políticos (la «malicia natural de los caciques»). Esta postura problematiza el americanismo y el indigenismo de Darío. No se trata de una defensa dogmática acrítica frente a una inmoralidad antidemocrática viciada por la corrupción del poder, como defecto propio de los países hispanoamericanos. Una «malicia» que Darío pareciera considerar ancestral. En este fragmento, el autor hace uso de su experiencia vivencial, se construye como testigo en la crónica y proporciona un testimonio de época.

Darío insiste en la necesidad de que diplomáticos como Arellano escriban sus memorias que testimonien las experiencias en los países centroamericanos «tan desconocidos aquí como en Europa». Esa falta de conocimiento la atribuye no tanto a la indiferencia de los países europeos por aquellos que no se les asemejan, sino más bien a la ausencia de testimonios escritos que dejen su huella y llamen la atención sobre los países centroamericanos.

Finaliza este núcleo temático con una dura crítica y denuncia contra el afán imperialista de Estados Unidos de Norteamérica:

[...] dejaria constancia de sucesos y cosas que mas tarde va á ser difícil reconstruir; digo mas tarde, cuando los Estados Unidos despues de la tajada del Canal, se ingurgiten todo ese istmo rico y tentador, por lo tanto, á su insaciable apetito, á sus tragaderas y á su buche, en donde existe la misma pepsina que en el buche fenomenal de su pariente John Bull.

(Darío, El Orden, 03/11/1898: 1).

Por último, en el cuarto núcleo temático, Darío se detiene en el ámbito de las letras, comentando como novedad literaria un texto de Belisario J. Montero, sin proporcionar datos editoriales ni el título del libro. Define dicho texto en una frase simple: «Es un libro dandy» y justifica tal afirmación con la evidencia de que todo en él tiene una «marca de distinción». Con tan pocos elementos, Darío condensa toda una concepción crítica de perspectiva modernista, con una precisión propia de un cirujano del estilo. Destaca, además, 
el idealismo presente en el libro, muy del gusto de su postura anti-positivista. ${ }^{16}$ A su vez, identifica las influencia detrás del estilo de Montero, razones en que apoya su juicio crítico: Stendhal, Maurice Barrès y, sobre todo, Barbey d'Aureville, la máxima expresión, según Darío, del dandismo. Sobre este escritor sostiene que «Gustar de Barbey es desde luego una señal de superioridad intelectual y de gentileza de espíritu» (Darío, El Orden, 03/11/1898: 1). A partir de esta caracterización del gusto literario ideal, se cierra el apartado y finaliza la crónica con una exaltación de los escritores que se preocupan por un estilo elaborado de escritura. En ellos podemos percibir un contraste entre la opción esteticista de la escritura frente a la meramente informativa de la crónica periodística, opción que desvela lo que Liliy Litvak ([1975] 1981: 12) identifica como una reacción a las preferencias materialistas dominantes de la burguesía que tanto desprecia y a la que, paradójicamente, dirige su texto. Paradoja que pone de manifiesto las contradicciones de la modernidad (Berman: 27 y Gutiérrez Girardot: 43)

Esta misma paradoja se expresa en la siguiente carta de Darío publicada en El Orden, y anunciada el viernes 25 de noviembre de 1898. El anuncio, en esta oportunidad, es una nota brevísima, básicamente informativa, que destaca un juicio de valor sobre la carta: «[...] es bella como todo lo que produce aquel privilegiado talento» (El Orden, 25/11/1898: 1). Como puede observarse, esta valoración se encuentra determinada por la firma consagrada y el valor simbólico de la posesión de sus escritos.

La segunda crónica de Darío se publica en El Orden el sábado 26 de noviembre. La fecha de la misiva es del día 20 y, al igual que la anterior, se publica en las primeras columnas del diario, contiene la firma del autor, la aclaración de exclusividad entre paréntesis y en ella aborda, asimismo, cuatro núcleos temáticos: el primero versa sobre cuestiones económicas en relación al aumento del papel; el segundo, retoma el tema de la exposición nacional enfocado ahora en un grupo nativo expuesto; el tercero se refiere al monumento de Garibaldi en Buenos Aires y el cuarto se detiene en muestras y exposiciones de arte. Como puede observarse, las temáticas abordadas son mucho más diversas que la primera carta.

La crónica comienza directamente con el primer núcleo temático, con un inicio un tanto repentino en comparación con la introducción de la primera

16. Claude Fell señala el desarrollo del idealismo, al que se adhiere Darío, como una postura que reacciona al positivismo predominante en la época (Fell, 2010: 166). El antipositivismo de Darío, y del modernismo como movimiento, también ha sido señalado por Gutiérrez Girardot, Ángel Rama, Jitrik, Litvak. Para Octavio Paz, el modernismo constituyó una «respuesta al positivismo» (Paz, [1975] 1981: 105). 
misiva, como si se tratara de una conversación interrumpida: «Ya estaréis al tanto de las discusiones y encuentros de juicios, cálculos y profecías que ha producido el alza rápida del papel [...]» (Darío, El Orden, 26/11/1898: 1). El conflicto del papel es el tema que motiva las opiniones de Darío sobre la política económica del país.

El segundo núcleo temático es un poco más extenso y predomina en él otra cara de la Exposición Nacional de 1898, que revela su lado negativo y contrasta con el tono exaltado ante el progreso industrial, palpable en la carta anterior. En este apartado, Darío relata su experiencia de contemplar al pueblo originario de los onas, del sur de Argentina, representado por un par de familias literalmente expuestas conviviendo en una choza exclusivamente construida para la muestra.

El tercer núcleo de esta segunda carta aborda una celebración de la comunidad italiana en Argentina en el momento de colocación del monumento de Garibaldi, erigido en héroe nacional. Resultan elogiosas las palabras de Darío sobre los italianos y su significativa y continua contribución al progreso argentino, así como el afecto por este país demostrado por dicha comunidad en reiteradas oportunidades. Asimismo, retrata la figura de Garibaldi desde su lado legendario, indicando que su devoción inspira la «poesía de héroe antiguo en nuestra vida secular» (Darío, El Orden, 26/11/1898). Lo considera un verdadero «specimen representativo superior del latino», próximo a Byron en su imagen romántica, y como símbolo para la juventud intelectual argentina.

Por último, en el cuarto núcleo temático, Darío se detiene en cuestiones de arte. En este apartado predomina el aspecto informativo de la crónica periodística con algunas observaciones de críticas sobre arte y sobre las personalidades que conoce y comenta. En primer lugar, exalta y recomienda las próximas presentaciones de las obras de Eduardo de la Cárcova en la Exposición Nacional, uno de los artistas que Darío promueve por coincidencia de ideas sobre arte y profesionalización (Malosetti Costa, 2004: 114). Luego se detiene en la exposición de Pío Collivadino en El Ateneo de Buenos Aires, con observaciones que intercalan datos sobre su obra plástica e información biográfica del artista argentino. Continúa informando sobre la presencia del escultor ruso Michel Kaplan en la capital argentina y anuncia la realización de algunas obras en la ciudad para dejar huellas de su paso por el país. Finalmente, se detiene en otra novedad, la visita del pintor romano Achille de Dominice, de quien destaca la belleza y maestría del dibujo. Cierra el apartado anunciando un próximo estudio en profundidad sobre estos artistas y con esta promesa finaliza su carta. 
Contrastes en la ciudad modernizada, una visión esteticista y humanitaria

Con respecto al núcleo temático de los onas en la exposición nacional de 1898 tratado por Darío en la segunda crónica publicada por El Orden, resulta necesario señalar ciertas consideraciones contextuales significativas. Según Ballestero, las exposiciones industriales europeas y norteamericanas organizadas a fines del siglo XIX, se convierten en espacios ideales para incorporar indígenas «reales» como parte de la muestra. Esta incorporación de «rarezas humanas» forma parte del divertimento y el espectáculo circense del evento. Ante tal presencia, estos eventos llaman la atención de la comunidad científica, sobre todo de los antropólogos, quienes encuentran en ellos el espacio ideal para realizar observaciones de grupos indígenas como especímenes humanos primitivos de pronta extinción, ahorrándose las complicaciones de los viajes a los lugares naturales de su procedencia (Ballestero, 2012: 790). El grupo expuesto en la muestra de la industria nacional de 1898 se compone de dos familias onas. De su traslado y disposición se encarga el propio gobernador de Tierra del Fuego, el Teniente Coronel Pedro Godoy. Luego de ser colocadas sus carpas en distintos puntos del predio, finalmente quedan instalados en la sección femenina de la Exposición (Ballestero, 2012: 794).

En la crónica publicada por El Orden, Darío cambia el tono de elogio predominante en la primera carta, por uno de indignación y de dolor, que señala la contracara de la modernidad. Como es usual en sus crónicas, destaca lo positivo y lo negativo a través de su mirada cosmopolita de la metrópoli (Montaldo, 2013: 46). De este modo, se pone en evidencia su postura humanitaria -más que indigenista- hacia los pueblos originarios expuestos en la muestra, su rechazo al modo de divertimento burgués representado por la exposición y su condena a la transformación del hombre como objeto de una muestra industrial, similar a la condena del mundo del rey burgués en su cuento homónimo de Azul... (Rama: 49). Darío se pregunta: «¿Hasta qué punto existe el derecho, en el hombre civilizado, de aprisionar como un simple babuino á un semejante en estado más o menos primitivo y hacerle objeto de la pública curiosidad, ó del público divertimento?» (Darío, El Orden, 26/11/1898: 1)

Evidentemente, Darío conoce la repercusión tanto social como periodística de la exposición de los onas en Buenos Aires. Su crónica expresa su postura frente a los comentarios de carácter positivista y seudo-cientificista, que rechaza, provenientes de las notas de los diarios porteños de la época.

Desde su mirada subjetiva, describe el estado en que se encuentran dichos hombres en la muestra. Emplea la ironía, el sarcasmo y los contrastes evidentes para un observador social atento. El estado primitivo, cercano al salvajismo, destacado en la vestimenta de pieles, en la desnudez de sus piernas y de 
partes del cuerpo, junto con el comportamiento abúlico de los integrantes del grupo, conforman un cuadro nada agradable para el adorador de la modernidad. La escena desentona con la Exposición, el primitivismo nativo no tiene cabida en la metrópoli moderna y contrasta como una rareza. A su vez, la descripción que hace Darío pone en primer plano el aturdimiento y confusión del grupo expuesto:

Allí están los indios azorados, nostálgicos de su existencia libre, [...] están envueltos en sus pieles, con sus hijos y sus perros; miran a las gentes que les contemplan ya con indiferencia, ya con asombro igual y recíproco; no ríen, se diría que no saben reir; les caen las greñas oscuras y lacias por los hombros; un indio zahareño se acurruca, al lado de sus flechas, y clava en quien le observa una mirada que es una flecha negra; una indiecita de quince años tiene desnudas las piernas finas y los pies de señorita salvaje, pulidos por el pedicuro de la naturaleza, chicos y monos, treinta veces mas lindos que su cara; un indiecito boquiabierto, está fraternalmente al lado del perro, que él sí, se diría lleno de una rara y vivaz inteligencia (Darío, El Orden, 26/11/1898: 1).

Como puede observarse el tono irónico y sarcástico predomina en esta imagen del grupo ona y resalta con fuerza contradictoria frente a la pregunta retórica humanitaria del inicio de la crónica. El grupo desentona, no es atractivo a la vista. Darío revela la necesidad de mostrar lo grotesco de la escena para resaltar la inutilidad y gratuidad de su exposición, además de representar, para los estetas modernistas como él, lo que se considera de «mal gusto». Esta observación señala la vulgaridad burguesa que disfruta de la rareza humana en la muestra e intensifica, de este modo, su contradicción: la exposición de primitivismo en el progreso industrial moderno. Esta vulgarización es una manifestación de la prosa del mundo que Gutiérrez Girardot destaca del pensamiento de Hegel en su interpretación de la modernidad (44) y que magistralmente señala el cronista modernista.

A continuación, se insiste en la manifestación del sentimiento de incomodidad de los onas expuestos en su cotidianidad ante la mirada de los paseantes. El cronista señala la recíproca mirada de extrañeza por parte de los nativos y de los espectadores que los contemplan. Miradas entre extraños que potencia la desigualdad de los expuestos, frente a los paseantes ocasionales. La escena del «indio hosco» y la dama que cruzan sus miradas, sin experimentar atracción alguna, representa gráficamente esa sensación de límite:

Está allí el grupo, como incómodo entre los ruidos de las máquinas y esos sones de las músicas y ese ir y venir de los hombres civilizados. Y el indio hosco vé á la bella dama q' pasa, sin admiracion profunda y se diria sin deseo; á lo más, esa maravilla blanca y rosa, le llamará la atencion por sus sedas y joyas, sus sombreros de pájaros y flores, sus sombrillas lila ó clavel, á la luz del flamante verano. Estos pobres seres traidos de la costa del sur no tienen 
aqui, ciertamente, atractivo alguno, como no sea el de ejemplares de jardin de aclimatación; y esa indiecita chica de los pequeños pies, no creo que sea en nada comparable á la jóven pampa Lokoma, que hoy es castellana y condesa en Francia (Darío, El Orden, 26/11/1898: 1).

La conmiseración que muestra el cronista deviene en un rechazo que responde a su mirada modernista: el grupo ona no pertenece a la ciudad, desentona con el progreso de la máquina, no aporta nada a la modernidad, salvo la rareza de los grupos expuestos en los «jardines de aclimatación»; por lo tanto, su aislamiento y colocación como objeto de vitrina en una exposición industrial sólo representa una muestra de una cultura disonante, un «otro» absoluto en la metrópoli. En este sentido, la postura de Darío, claramente anti-positivista, rechaza la aparente curiosidad entre seudo-cientificista y morbosa propia del esnobismo de los paseantes intrigados por las culturas «otras», tan en boga gracias al cientificismo divulgado por los diarios de la época.

Se percibe, además, una clara alusión a la tendencia de exponer grupos humanos como rarezas circenses en exposiciones nacionales y, particularmente, a la exposición de fueguinos en el Jardin d'Acclimatation de París entre 1881 y 1882. Este evento, según Ballestero, fue muy comentado y aprovechado por los científicos europeos para el estudio de especímenes humanos, evento en el cual se comprobaría, además, la inferioridad racial de los habitantes del sur (2012: 792). La exposición de los indígenas en un gran evento citadino representa una forma de domesticación: se vuelven parte de un espectáculo de la ciudad que los observa. Ésta es precisamente la postura que rechaza Darío, exponer para el divertimento burgués a seres de otras culturas que considera como semejantes, el hombre objeto del hombre. Esta denuncia de la cosificación es marca de los escritores modernistas y de los artistas de la época, tal como lo han analizado Benjamin, Berman, Gutiérrez Girardot y Rama, entre los estudiosos más reconocidos.

Por otra parte, Darío reconoce, no obstante, el grado de primitivismo en el que se encuentra la población indígena expuesta, reconocimiento que, inevitablemente, acataría el discurso evolucionista de la época, que aparentemente rechaza. Este reconocimiento, esta coincidencia de representación del otro, como guiño al público que lee sus crónicas, es una marca de evidente contradicción en su discurso. Contradicción que revela la dialéctica entre modernidad y modernización en la que están envueltos los mismos escritores modernistas. En este sentido, el reconocimiento del primitivismo pone en evidencia la contradicción de la modernidad en Argentina, que vive un desarrollo acelerado en la portuaria Buenos Aires, pero mantiene formas de vida primitiva en sus regiones internas. Este desarrollo desequilibrado se asemeja 
a lo que Berman denominó «modernismo del subdesarrollo» ([1982] 1989: 239), propio de los países considerados retrasados como sucede en Rusia con San Petersburgo, frente a las grandes ciudades europeas con París como la metrópoli ideal mundial. Un modernismo truncado, basado fundamentalmente en «espejismos» $y$ «fantasías de la modernidad» y de su lucha contra ellos. Berman observa: «Pero la realidad grotesca de donde emana este modernismo, y las presiones insoportables bajo las cuales vive y se mueve -presiones que son tanto políticas y sociales como espirituales- le infunden una incandescencia desesperada que el modernismo occidental (...) raramente puede esperar alcanzar» (239-240). Podría decirse que esta misma perspectiva es la que Darío manifiesta en su crónica.

Por otra parte, cabe destacar el detenimiento de la mirada del cronista en la joven ona expuesta y la imagen con la que la contrapone, la de la jovencita «pampa Lokoma». Esta alusión revela la erudición literaria de Darío y su memoria libresca y periodística. Dicha mención remite al Viaje al Río de la Plata. Tres meses de vacaciones de Emilio H. Daireaux, publicado por entrega en La Ilustración. Revista de Hipano-América (Barcelona) a lo largo de aproximadamente un año, entre el 23 de octubre de 1887 y el 16 de octubre de 1888. En dicho texto, Daireaux relata, en el número 400 de la revista, una de las famosas campañas al desierto, la que involucra la «Zanja de Alsina», antes de la agresiva «Conquista del Desierto» dirigida por el General Roca, y la crueldad de la metodología empleada para someter a los nativos: las excavaciones de zanjas que buscaban detener los ataques y robos de los malones indígenas e impedían a los nativos llegar al ganado de las estancias. El hambre y las enfermedades logran doblegar parte de la población indígena. El Estado argentino decide trasladar a los sobrevivientes a Buenos Aires y, como no puede hacerse cargo de tanta cantidad de gente, se decide entregar las mujeres y niños a los ciudadanos interesados en recibirlos como criados. La joven Lokoma, según relata Daireaux, fue adoptada y criada por la Condesa de Amelot de Chaillou, cuyo esposo era representante de Francia en Buenos Aires en esa época. Daireaux señala el ejemplo exitoso de esta jovencita para contrarrestar el determinismo de los antropólogos cientificistas que condenan como inferior a los nativos de América:

Los exquisitos cuidados de que ha sido objeto, la educación que ha recibido y forman de ella una estimable doncella de quince años, da un mentís á la ciencia antropológica, al convertir á la hija de una raza primitiva, á la que se creía incapaz de comprender y de recibir nuestra civilización, en una joven digna de la persona que la ha dirigido por modo tan elevado y del medio en que ha sido educada (Daireaux, La Ilustración, 01/07/1888: 429). 
El contraste con la imagen de la ona de la crónica salta a la vista, dada la diferente suerte de ambas jóvenes. La explícita expresión de aburrimiento que señala Darío delata la naturaleza humana sometida y la resignación de su situación. Cierra el apartado la irónica observación «seudo antropológica» del autor: "Son unos tristes ejemplares de animal humano de nuestras costas, y con aires justamente aburridos; nada más» (Darío, El Orden, 26/11/1898: 1). Esta observación final, potenciada con el enfático «justamente aburridos», resalta implícitamente la operación de desequilibrio provocada por la organización del evento, precisamente porque el grupo pertenecería al ámbito de la naturaleza (no de la modernidad metropolitana) de la cual fue extraído para la muestra. Podría percibirse su defensa del indígena en esta consideración de los onas como gente fuera de contexto, gente aburrida y molesta por ser observados (cosificados) por otra gente, con otros hábitos.

En la crónica, Darío no contrapone a la categoría de «hombres civilizados» la de «bárbaros», en consonancia con la antinomia «civilización» y «barbarie», comúnmente empleada para contrastar imágenes entre ciudad y campo, que ya forman parte de la jerga literaria y periodística de la época, cuya vigencia se debe a Domingo Faustino Sarmiento (Lojo, 1994: 11). El nicaragüense prefiere emplear la categoría «pobres seres» para enfatizar su calidad humana y su condición de prisioneros o cautivos en una exposición nacional. Es interesante la denuncia articulada en su discurso que muestra a los hombres civilizados que «aprisionan» seres en estado primitivo. Sin embargo, el texto de Darío, tal como observamos, pasa de una perspectiva de denuncia (de una situación de opresión y de esclavitud por la que los «civilizados» someten a los indígenas para divertimento burgués) a una mirada estética moderna (los onas desentonan entre los progresos de la modernidad).

El artículo, sin embargo, más allá de las connotaciones esteticistas evidentes, contiene una clara denuncia y solicita, por ello mismo, una lectura acorde con el tono irónico y sarcástico predominante propio de la crítica social. En este punto, no consideramos que la postura indigenista de Darío sea sólo literaria, tal como lo plantea Jorge Camacho (2012: 11), sino también de defensa de la condición humana, tal como se evidencia en esta crónica, propia de las denuncias configuradas por los modernistas contra la deshumanización y la crueldad de las costumbres burguesas y de la modernidad, que convierten al hombre en objeto del hombre, tal como señalamos anteriormente siguiendo a Gutiérrez Girardot. En todo caso, se puede afirmar que su postura con respecto a la alteridad es compleja y debe ser estudiada con detenimiento, teniendo en cuenta no sólo su perspectiva esteticista, sino también la de denuncia y crítica social. Ambas, precisamente por su 
combinación irónica y paradójica en la crónica metropolitana, constituyen la postura crítica del modernismo como visión y respuesta a los efectos de la modernidad en la vida social.

Como puede apreciarse, las observaciones de la exposición de los onas por parte de Darío se presentan claramente opuestas a las expresadas en crónicas periodísticas como las publicadas por La Prensa en la misma época, que representan la mirada dominante del conformismo burgués y mundano que disfruta del espectáculo. Este contraste pone en evidencia las diferencias sustanciales entre la crónica modernista (como respuesta del modernismo al mundo burgués al que su vez se dirige) y la crónica periodística (informativa y acorde al público burgués que no cuestiona). En efecto, en dicho periódico aparece el 7 de noviembre de 1898, un artículo sin firma titulado «Los onas. Su vida y costumbres. Ideas sobre las prácticas de las sociedades civilizadas. Una visita a los que se exhiben en el certamen nacional». ${ }^{17}$ En el texto se denomina al grupo como «retardatarios de la humanidad que viven aun en territorio argentino» (La Prensa, 07/11/1898, reprod. por Ballestero: 807) y se anuncia su pronta desaparición por el avance de la civilización. Esta insistencia en el progreso civilizatorio es uno de los puntos que precisamente ironiza la crónica de Darío: son estos civilizados los que aprisionan a seres semejantes. El texto de La Prensa destaca la «rareza» del grupo expuesto, lo que motiva la curiosidad de la gente. Este punto también es criticado, tal como vimos, por Darío a través de una pregunta retórica sobre lo innecesario de exponer seres para el divertimento mundano.

La consideración de la mirada no indiferente de los onas y su incomodidad son también alusiones contrastantes con el tono del artículo de La Prensa, en el cual se sostiene:

Los onas, indiferentes a la mirada de los curiosos, toman con la mayor despreocupación, posiciones cómodas; ocupanse descansadamente de recordar las cosas de su tierra, o en comentar a su modo la admiración de que son objeto; comen a la vista del público, fuman, juegan, ríen; y, sobre todo, cuando logran librarse de la conversación de los cristianos, detiénense en admirar los objetos mas insignificantes, extraños para ellos (La Prensa, 07/11/1898, reprod. por Ballestero: 807). ${ }^{18}$

Obsérvese en la cita cómo se hace alusión a la risa, lo que Darío niega rotundamente como expresión del grupo, al sostener que «no saben reir» (Darío, El Orden, 26/11/1898: 1).

17. Artículo reproducido por Ballestero en el apéndice de su trabajo (2012: 807-810).

18. Lo resaltado en cursiva corresponde al original. 
A pesar de esta observación de la postura cómoda de los onas en la ciudad, La Prensa interpreta en sus gestos, no tanto incomodidad, sino nostalgia por su propia tierra, nostalgia de la libertad, lo que inmediatamente es juzgado como actitud propia del «salvajismo». Otro punto destacable de comparación de esta crónica con la de Darío es la supuesta indiferencia hacia la mirada del otro que observa y a su vez es observado, cuando destaca las palabras de uno de ellos, Manuel, quien sostiene que en su tierra no hay tanta «gente curiosa». Como vimos, Darío toma precisamente estos aspectos, los de la extrañeza de la mirada, la sensación de libertad coartada, para señalar la justificada actitud de aburrimiento del grupo.

\section{Consideración final}

La presencia de Darío en Argentina deja sus huellas, no sólo en los diarios de Buenos Aires, sino también, con sus esporádicas colaboraciones, en un periódico de provincia. En El Orden de Tucumán se manifiesta su preferencia por la crónica, cuyas características responden a los lineamientos de la crónica modernista señalados por la crítica y los estudiosos literarios. En sus textos, con fuertes trazos esteticistas, encontramos elementos que problematizan, dada la marcada impronta irónica predominante, tanto su postura americanista como indigenista.

La actitud anti-imperialista hacia los Estados Unidos de Norteamérica se manifiesta en la primera carta de forma explícita. Por contraste, se deduce su defensa de los países hispanoamericanos, sobre todo centroamericanos, sometidos y víctimas de los avances invasivos de Estados Unidos. Su evidente conocimiento de los países de América Central y de la situación de corrupción política de la que son víctimas también se manifiesta claramente en esta primera carta cuando se detiene en la caracterización del ministro Arellano. Allí se explicita su defensa de dichos países, en una narración ficticia sobre una posible crónica escrita por diplomáticos centroamericanos que relaten las fantásticas aventuras en calidad de mediadores de arreglos pacíficos de situaciones delirantes en "países imposibles». En dicha defensa se manifiesta una fuerte crítica a los dirigentes políticos, en la que incluye a los altos líderes indígenas, cuyos comportamientos igualmente corruptos denuncia.

La postura indigenista de Darío se expresa en la segunda carta como una manifiesta posición humanitaria con respecto a la muestra de onas en la Exposición Nacional de 1898. De la denuncia por la situación denigrante a la que se encuentran sometidos los miembros del grupo expuesto, Darío torna por momentos su mirada hacia una crítica estética. Los onas desentonan con la modernidad de la muestra. Su exposición se presenta ante sus ojos como 
propia de un «jardín de aclimatación», una muestra de rarezas de la naturaleza, y no como parte del mundo industrial. Dicha exposición representa una evidente contradicción de la modernidad.

\section{Bibliografía}

AlONSO, Paula, Entre la revolución y las urnas. Los orígenes de la Unión Cívica Radical y la política argentina en los años '90, Buenos Aires, Editorial Sudamericana / Universidad de San Andrés, 2000.

ANÓNimo, «Rubén Darío», El Orden, San Miguel de Tucumán, miércoles 02 de noviembre de 1898 , p. 2.

ANÓNIMO, «Rubén Darío», El Orden, San Miguel de Tucumán, viernes 25 de noviembre de 1898, p. 1.

Ballestero, Diego A., «Los fueguinos, Robert Lehmann-Nitsche y el estudio de los onas en la Exposición Nacional de Buenos Aires de 1898», História, Ciências, Saúde - Manguinhos, Rio de Janeiro, vol. 18, N 3, jul.-set. 2011, pp.789-810.

BARCIA, Pedro Luis: «Rubén Darío en la Argentina», en Darío, Rubén, Escritos dispersos de Rubén Darío (recogidos de periódicos de Buenos Aires), La Plata, Departamento de Letras, Instituto de Literatura Argentina e Iberoamericana, Universidad Nacional de La Plata, Facultad de Humanidades y Ciencias de la Educación. Tomo I, 1968, pp. 11-76.

Battilana, Carlos, «Rubén Darío. Periodismo y enfermedad», en Zanetti, Susana (Coord.), Rubén Darío en La Nación de Buenos Aires 1892-1916, Buenos Aires, EUDEBA, 2004, pp. 123-138.

Benjamin, Walter, El París de Baudelaire, Buenos Aires, Eterna Cadencia Editora, 2012 [1974]. Traducido por Mariana Dimópulos.

Berman, Marshall, Todo lo sólido se desvanece en el aire, Buenos Aires, Siglo XXI Editores, [1982] 1989.

BOURDIEU, Pierre, Las reglas del arte. Génesis y estructura del campo literario, Barcelona, Anagrama, 1992.

CAMACHO, Jorge, «José Martí y Rubén Darío ante la anexión de los territorios indígenas en Argentina y Nicaragua», Decimonónica, vol. 9, № 2, verano 2012, pp. 1-17.

Carilla, Emilio, Ricardo Jaimes Freyre, Buenos Aires, Ediciones Culturales Argentinas, Ministerio de Educación y Justicia, Dirección General de Cultura, 1962.

Carilla, Emilio, Una etapa decisiva de Darío (Rubén Darío en la Argentina), Madrid, Gredos, 1967. 
Daireaux, Emilio H., «Viaje al Río de la Plata. Tres meses de vacaciones», La Ilustración. Revista Hispano-Americana, Barcelona, $\mathrm{N}^{\circ} 400,01$ de julio de 1888, Año 9, pp. 428-429.

Darío, Rubén, «De Rubén Darío», El Orden, San Miguel de Tucumán, jueves 03 de noviembre de 1898, p. 1.

— «De Rubén Darío», El Orden, San Miguel de Tucumán, sábado 26 de noviembre de 1898, p. 1.

- Vida de Rubén Darío escrita por él mismo, Barcelona, Maucci, 1913.

- Escritos inéditos recogidos de periódicos de Buenos Aires, Mapes, E.K. (comp.), Nueva York, Instituto de las Españas en los Estados Unidos, 1938.

- Autobiografía. «In memoriam» por José Enrique Rodó, Buenos Aires, Editorial El Quijote, 1947.

- Escritos dispersos de Rubén Darío (recogidos de periódicos de Buenos Aires), Barcia, Pedro Luis, «Estudio preliminar, recopilación y notas», La Plata, Departamento de Letras, Instituto de Literatura Argentina e Iberoamericana, Universidad Nacional de La Plata, Facultad de Humanidades y Ciencias de la Educación. Tomos I, 1968 y Tomo II, 1977.

- Viajes de un cosmopolita extremo, Selección y prólogo de Graciela Montaldo. Buenos Aires, Fondo de Cultura Económica, 2013.

FELl, Claudio, «El ensayo hispanoamericano y la reflexión sobre la identidad (1890-1930)», en Puccini, Darío y Yurkievich, Saúl, Historia de la cultura literaria en Hispanoamérica, Tomo II, México, Fondo de Cultura Económica, 2010, pp. 141-171.

Galasso, Norberto, El ciclo de Roca, Buenos Aires, Cuadernos para la Otra Historia, vol. 15, Centro Cultural «Enrique Santos Discépolo», 2000.

GARCía Soriano, Manuel, El periodismo tucumano: 1817-1900, Tucumán, Cuadernos de Humanitas 38, Universidad Nacional de Tucumán, Facultad de Filosofía y Letras, 1972.

GONZÁlez, Aníbal, La crónica modernista hispanoamericana, Madrid, Ediciones José Porrúa Turanzas S. A., 1983.

GutiÉRrez GiRARdot, Rafael, Modernismo. Supuestos históricos y culturales, Colombia, Fondo de Cultura Económica, 2004 [1983].

Henríquez UReña, Max: Breve historia del modernismo, Buenos Aires, Fondo de Cultura Económica, 1978.

Jitrik, Noé, Modernismo, Buenos Aires, Centro Editor de América Latina, 1985.

LITVAK, Lily (ed.), El modernismo, Madrid, Taurus, [1975] 1981.

LOJO, María Rosa, La «barbarie» en la narrativa argentina (Siglo XIX), Buenos Aires, Corregidor, 1994.

Malosetti Costa, Laura, «¿Un Ruskin en Buenos Aires? Rubén Darío y el Salón del Ateneo de Buenos Aires, en 1895», en Susana Zanetti (Coord.), Rubén 
Darío en La Nación de Buenos Aires 1892-1916, Buenos Aires, EUDEBA, 2004, pp. 105-121.

MarTínez ZuCCARDI, Soledad, Entre la Provincia y el Continente. Modernismo y modernización en La Revista de Letras y Ciencias Sociales (Tucumán 1904-1907), Tucumán, IIELA, Facultad de Filosofía y Letras, UNT, 2005.

MOGILLANSKY, Gabriela, «Modernización literaria y renovación técnica: La Nación (1893-1898)», en Susana Zanetti (Coord.), Rubén Darío en La Nación de Buenos Aires 1892-1916, Buenos Aires, EUDEBA, 2004, pp. 83-104.

Montaldo, Graciela, «Guía Rubén Darío», en Darío, Rubén, Viajes de un cosmopolita extremo. Buenos Aires, Fondo de Cultura Económica, 2013, pp. 11-51.

PAZ, Octavio, «Traducción y metáfora» (de Los hijos de limo, 1974), en Litvak, Lily (ed.), El modernismo, Madrid, Taurus, [1975] 1981, pp. 97-117.

Persello, Ana Virginia, «La Unión Cívica Radical. De los orígenes a la emergencia del peronismo», en Iberoamérica Global, vol. 4, núm. 2, noviembre de 2011, pp. 80-98.

PuCcini, Darío y Yurkievich, Saúl, Historia de la cultura literaria en Hispanoamérica, Tomo II, México, Fondo de Cultura Económica, 2010.

RAmA, Ángel, Rubén Darío y el modernismo, Caracas / Barcelona, Alfadil Ediciones, 1985.

- La ciudad letrada, Montevideo, Arca, 1998.

Ramos, Julio, Desencuentros de la modernidad en América Latina. Literatura y política en el siglo XIX, Caracas, Venezuela, Fundación Editorial El Perro y la Rana, 2009.

RISCO, Ana María, Comunicar literatura, comunicar cultura. Variaciones en la conformación de la página literaria del diario La Gaceta de Tucumán entre 1956 y 1962, Tucumán, Serie Tesis, Departamento de Publicaciones, Facultad de Filosofía y Letras, UNT, 2009.

Rivera Montealegre, Flavio, Rubén Darío. Su vida y su obra, Estados Unidos de Norteamérica, iUniverse, 2012.

Simmel, Georg, «Die Grosstädte und das Geistesleben», in Die Grossstadt. Vorträge und Aufsätze zur Städteausstellung. Jahrbuch der Gehe-Stiftung Dresden, Dresden, hrsg. von Th. Petermann, Band 9, 1903, S. 185-206.

- «La metrópoli y la vida mental», Sobre la individualidad y las formas sociales. Escritos escogidos, Buenos Aires, UNQui-Prometeo, 2002, pp. 388-402. También en Bifurcaciones, núm. 4, 2005. Editado por Donald N. Levine. Disponible en http://www.bifurcaciones.cl/004/bifurcaciones_004_reserva. pdf

Williams, Raymond, Marxismo y literatura, Barcelona, Península, 2000 [1977].

ZANETTI, Susana (Coord.), Rubén Darío en La Nación de Buenos Aires 1892-1916, Buenos Aires, EUDEBA, 2004. 
— «Rubén Darío en La Nación de Buenos Aires (1892-1916)», en Zanetti, Susana (Coord.), Rubén Darío en La Nación de Buenos Aires 1892-1916, Buenos Aires, EUDEBA, 2004, pp. 9-59.

Fecha de recepción: 17/03/2014

Fecha de aceptación: 09/07/2014 